\title{
Barriers and facilitators of the implementation of Individual Placement and Support (IPS) for patients with offending histories in the community: The UK experience
}

\begin{tabular}{|r|l|}
\hline Journal: & British Journal of Occupational Therapy \\
\hline Manuscript ID & 041-Feb-2019-RP.R2 \\
\hline Menuscript Type: & Research Article \\
\hline Keywords: & Clinical \\
\hline individual placement and support, implementation, barriers, facilitators, \\
offenders
\end{tabular}

\section{SCHOLARONE




\title{
Barriers and facilitators of the implementation of Individual Placement and Support (IPS) for patients with offending histories in the community: The UK experience
}

\begin{abstract}
Introduction: We aimed to identify the barriers and facilitators to the implementation of a high fidelity IPS service in a community forensic mental health setting.
\end{abstract}

Method: In-depth interviews were conducted with clinical staff $(n=11)$, patients $(n=3)$, and employers $(n=5)$ to examine barriers and facilitators to implementation of a high fidelity IPS service. Data was analysed using thematic analysis, and themes were mapped onto IPS fidelity criteria.

Results: Barriers cited included competing interests between employment support and psychological therapies, perceived patients' readiness for work, and concerns about the impact of returning to work on welfare benefits. Facilitators of implementation included clear communication of the benefits of IPS, interdisciplinary collaboration, and positive attitudes toward the support offered by the IPS programme among stakeholders. Offences, rather than mental health history was seen as a key issue from employers' perspective. Employers regarded disclosure of offending or mental health history as important to develop trust and to gauge their own capacity to offer support.

Conclusion: Implementation of IPS in a community mental health forensic setting is complex and requires robust planning. Future studies should address the barriers identified and adaptations to the IPS model are needed to address difficulties encountered in forensic settings. 


\section{Key words:}

Individual placement and support, implementation, employment, offenders, mental disorder, barriers, facilitators.

\section{Word counts}

$\begin{array}{ll}\text { Abstract: } & 199 \\ \text { Text: } & 6969\end{array}$




\section{Introduction}

The UK government regards employment as a means to aid mental health recovery and reduce reoffending rates (Ministry of Justice, 2013). Higher rates of unemployment exist among ex-offenders than in the general population, $47 \%$ and $12 \%$ respectively (Ministry of Justice, 2013). Nearly $60 \%$ of people released from prison re-offend within 3 years of their release (Pager, 2003) and among offenders sentenced to a prison sentence of under 12 months, higher reoffending rates are reported for those who do not enter employment than those who do, $69 \%$ and 32\% respectively (Ministry of Justice, 2013). The combination of stigma attached to incarceration, social isolation, substance use, and low educational attainment serves to perpetuate an inverse relationship between incarceration and subsequent employment (Western, 2002). Furthermore, ex-offenders face additional personal and social barriers to employment, including homelessness, lack of relevant skills, stigma and discrimination from employers (Centre for Mental Health, 2010; Talbot et al., 2018; Haslewood-Pocsik et al., 2008).

Specific lack of employment opportunities for ex-prisoners with severe mental illness is well documented (e.g., Hamilton, 2016). While several work skills programmes have been developed for this population, these programmes are primarily delivered in criminal justice settings and the evidence base for their effectiveness is limited. For instance, Talbot and colleagues (2017) reviewed published literature to determine the effectiveness of work skills programmes and reported that these programmes had no significant impact on mental health, substance use or reoffending rates, and their impact on helping people enter paid employment was modest. 
Effective approaches to helping people with offending histories gain employment share some of the features of Individual Placement and Support (IPS) (Samele et al., 2018), a form of evidence-based supported employment. IPS is regarded as the most effective approach in supporting people with severe mental illness to secure paid employment (Crowther et al, 2001; Burns et al, 2007; Rinaldi et al, 2008; Bond et al, 2008; Kinoshita et al, 2013; Modini et al., 2016; Metcalfe et al., 2018; Frederick and Vander Weele, 2019). The IPS model originated in the USA, but research evidence suggests that IPS transports well to other countries provided that programmes achieve high fidelity to the IPS model (Bond et al., 2012; Catty et al., 2008). For instance, the EQOLISE study (Burns et al., 2007) demonstrated the effectiveness of IPS in six European centres (London (UK), Ulm-Guenzburg (Germany), Rimini (Italy), Zürich (Switzerland), Groningen (Netherlands), and Sofia (Bulgaria)). Other studies demonstrated the effectiveness of IPS in the Netherlands (Michon et al., 2014), Sweden (Bejerholm et al., 2015), and Switzerland (Hoffman et al., 2012). In the UK, the SWAN trial (Howard et al., 2010) found no significant differences between IPS and traditional vocational services in obtaining competitive employment at 1-year follow up. Only at 2-year follow up was IPS found to be more effective than the control intervention (Heslin et al., 2011). While high IPS fidelity was attained in the SAWN trial, the concern was that the implementation lacked sufficient dosage to be effective. This is important since an effective intervention delivered at sub-therapeutic dose becomes an ineffective intervention (Latimer, 2010).

However, implementation of the IPS model in different social and economic contexts can be challenging and certain barriers may prevent IPS services from attaining high fidelity (Bergmarka et al., 2018; Nygren et al. 2011; Hasson et al., 2011). Of relevance to this 
discourse, are findings from studies that reported on the barriers and facilitators to IPS implementation in adult mental health settings.

\section{Literature review}

The extant literature identified several contextual, organisational and individual level barriers to IPS implementation (Bonfils et al., 2017). Key structural barriers include existing regulations for social insurance and employment (Hasson et al., 2011), poor interagency collaboration (Van Erp et al., 2007; Hasson et al., 2011), failure to provide employment support, global economic recession (Rinalidi et al., 2010) and conflict between national employment policies and local IPS schemes (Bonfils et al., 2017).

Organisational level barriers are numerous and include lack of organisational standards, inadequate funding and support for vocational programmes, lack of engagement from healthcare managers, poor management practices, resistance to change, negative attitudes among managers and clinicians about the feasibility of work for people with mental illness, scepticism about the organisational fit of IPS, and difficulties related to integration of the IPS service into local mental health teams (Bond et al., 2001; Van Erp et al., 2007; Hasson et al., 2011; Bonfils et al., 2017; Bergmarka et al., 2018). Other studies reported additional barriers like poor cooperation between employment specialists and mental health teams (Corbière et al., 2009), limited knowledge of IPS among clinicians (Shafer et al.,1999), negative attitudes towards employment among people with mental illness (Crane-Ross et al., 2000), limited knowledge of mental health issues among employment specialists (Handler et al., 2003), and reluctance of employment specialists to collaborate with clinicians due to feelings of 
intimidation (Handler et al., 2003) and concerns about the medical model predominating over the vocational approach to understanding the patients' problems (Drake et al., 2003).

Individual level barriers are limited knowledge of supported employment among clients and family members (Bond et al., 2001), concerns about the impact of IPS on welfare benefits (Hasson et al., 2011), fears that transition to work will have a negative impact on the individual and a culture of low expectations (Rinaldi et al., 2010).

Key facilitators of IPS implementation cited include the professional skills and dedication of IPS workers and the integration of IPS and mental health services (Van Erp et al., 2007; Bergmarka et al., 2018), the use of a fidelity scale to guide implementation and the employment of skilled professionals (Bonfils et al., 2017). Further, Becker and colleagues (1998) identified five areas that are critical for successful implementation of IPS; leadership, organizational structure, training, finance, and time frame.

\author{
Research on IPS implementation is an emerging field. Bonfils and colleagues (2017) \\ identified a lack of focus on the contextual differences between countries in relation to health, \\ employment, social care and welfare systems as a major limitation of studies of IPS \\ implementation (Bonfils et al., 2017). However, more recent studies addressed that by \\ focusing on contextual differences (e.g., Metcalfe et al., 2018; Richter \& Hoffman, 2018).
}

\title{
The present study
}

Community forensic mental health services in the UK provide treatment for individuals with mental disorders and offending histories, and aim to help individuals who are discharged 
from secure care make the transition back into the community (Joint Commissioning Panel for Mental Health, 2013). These services first began to evolve in 1992 and by 2006 there were 37 services in England and Wales alone (Judge et al., 2004). Whilst all services offered risk assessment and case management, only half offered specific psychotherapeutic interventions, some offering treatments for personality disorders $(40 \%)$, sex offenders $(36 \%)$ or substance use (16\%) (Judge et al., 2006). More recently, the Royal College of Psychiatrists set quality standards for these services (Kenney-Herbert et al., 2013), but the extent of adherence to these standards remains uncertain.

Whereas IPS is regarded as 'best practice' in adult mental health, the evidence base for IPS in forensic mental health settings is limited (Sneed et al., 2006). A notable exception is a study in the USA by Bond and colleagues (2015) which reported that IPS was superior to a control intervention that offered a job club approach with peer support in helping people with justice involvement secure competitive employment. However, the study reported no significant difference between the interventions in relation to justice involvement. More recently, Durcan and colleagues (2018) examined the effectiveness of IPS among prison leavers and reported that out of the 54 people who actively engaged in IPS, 21 (39\%) gained paid employment.

However, little is known about the barriers and facilitators to IPS implementation in criminal justice or forensic mental health settings. A study from the USA (Sveinsdottir and Bond, 2017) reported on barriers to employment in people with severe mental illness and criminal justice involvement, and identified poor engagement with vocational services as the main 
barrier to employment in this population, followed next by substance use. The study, however, did not discuss barriers and facilitators of IPS implementation. The present study helps fill an important gap in the literature and complement the findings of an earlier paper (citation) which described the process of IPS implementation in community forensic mental health settings. Using a qualitative research design, this paper provides further insights into the barriers and facilitators of IPS implementation in such settings through in-depth interviews with a sample of clinical staff, patients, and employers.

\section{Study objectives}

The specific objective of this study was to identify perceived barriers and facilitators to the implementation of high fidelity IPS programmes in community forensic mental health settings. The data is based on in-depth interviews with clinical staff, an employment specialist, employers, and patients.

\section{Method \\ Design}

The study was conducted as part of a feasibility cluster randomized trial of IPS in a large community forensic mental health service (blinded citation), including four clusters:

Cluster 1: City Community Forensic Service.

Cluster 2: County Community Forensic Service.

Cluster 3: City Personality Disorder Network.

Cluster 4: County Personality Disorder Network. 
Clusters 1 and 4 were randomly assigned to the intervention (IPS + treatment as usual (TAU)), and clusters 2 and 3 to the control group (TAU). TAU comprised case management (Clusters 1 and 2) or therapy only (Clusters 3 and 4).

\section{IPS implementation}

Details of IPS implementation and fidelity reviews are reported elsewhere (citation). It is important to distinguish implementation from fidelity reviews. Implementation entails transferring an effective programme into real world settings and maintaining them (Durlak and DuPre, 2008). In contrast, a fidelity review is an important aspect of implementation quality and assesses the extent to which a programme, in this case the IPS model, follows the eight principles of IPS (Bond et al., 2012).

The IPS model was implemented over 6 months. We used the Consolidated Framework for Implementation Research (CFIR; Damschroder et al., 2009) to guide the process of IPS implementation. The CFIR is comprised of five unified constructs: characteristics of the intervention, inner setting, outer setting, individuals involved, and implementation process. IPS fidelity reviews were completed by an independent IPS expert at the start and end of the implementation period using the IPS fidelity scale (Becker et al., 2008). IPS was delivered by an employment specialist who received supervision from a senior occupational therapist. An IPS steering group, chaired by a senior occupational therapist, was established to oversee the IPS implementation and delivery. A fair degree of fidelity (total IPS fidelity score $=85$ ) was achieved at the end of the implementation period. Table 1 provides a detailed breakdown of IPS fidelity scores.

Table 1 Here 


\section{Sample}

A sample reflecting a mix of backgrounds and experiences, including staff $(n=11)$, patients who received the IPS service $(n=3)$, and employers $(n=5)$, participated in in-depth interviews that examined views of IPS, and structural, organisational, and individual level barriers and facilitators to implementation of IPS in community forensic mental health settings.

Patients aged 18 years or over who were on the caseload of the community forensic services were eligible to participate. Those who were unable to provide informed consent, not entitled to work in the UK, currently in open employment or who did not wish to work were excluded. Patient recruitment took place over 6 months, and participants were followed up for 12 months from enrolment date. We set no exclusion criteria for staff or employer participants.

Eighteen patients participated in the feasibility trial -7 in the control arm and 11 in the IPS arm. Patient interviewees $(n=3)$ were drawn from the IPS arm, all were male. Two had degree level qualifications and were in paid employment, and one in a volunteering role at the time of the interviews.

Staff participants were recruited from the IPS arm of the community forensic mental health services and therefore had knowledge and experience of the IPS service, including community psychiatric nurses $(n=9)$, a psychiatrist, and the employment specialist within the service. 
Employer participants were recruited randomly from a list of employers compiled by the employment specialist during the study. Only two employers had direct experience of employing patients via IPS.

\section{Procedure}

Semi-structured interviews were conducted in private rooms within the community forensic service, or at the work place of employer participants. Interviews were conducted by a researcher and members of a 'Lived Experience Advisory Panel' (LEAP) who had received training in conducting the interviews. The interview schedule for staff and patient participants covered topics related to the participant's personal experience of IPS and barriers and facilitators to IPS implementation. The employer interview schedule covered topics related to their personal experience of employing people with mental disorders and offending histories, and barriers and facilitators to employing these individuals.

\section{Research ethics}

The study received approvals from the East Midlands research ethics committee and the Research and Innovations Department of the NHS Trust. Written informed consent was obtained from all participants.

\section{Data analysis}

The interviews were audio recorded and transcribed verbatim. The data was then imported into Nvivo 11 Pro data software managing tool. Data familiarisation entailed listening to the audio recordings and reading the transcripts prior to analysis. The analysis was conducted by researchers who were not involved in the data collection. Interviews were analysed using Braun and Clarke (2006) thematic analysis. The resulting themes were mapped on to IPS 
fidelity criteria. The benefit of this approach is that it helps separate barriers and facilitators to IPS implementation from aspects of IPS programme fidelity that have not been adequately implemented. The findings were then discussed in the LEAP meetings to further validate the results. The LEAP group met quarterly with the research team to provide advice on IPS implementation and the overall conduct of the study.

\section{Results}

The results are presented under separate headings in accordance with the IPS fidelity criteria (Becker et al, 2008) which when achieved act as a facilitator, and when not a barrier. The data is from staff (S), an employment specialist (ES), employers (E), and patients (P).

Zero Exclusion: To ensure fidelity, all clients interested in working should be offered IPS, regardless of job readiness, symptoms, violent behaviour, or treatment non-adherence. Clients should not be screened out or excluded.

However, staff reported that some of their patients were not ready for employment, although part of the process of embedding IPS into a service, and to get referrals of patients by clinical staff, was to host workshops and seminars as training is critical to the success of IPS implementation (Becker et al., 1998), which not only detailed what IPS consisted of, but also the associated patient-centred benefits. Even with this knowledge, staff still judged whether their patient was ready for work or not and made authoritarian decisions which were not patient-centred:

S1: Some [clinicians] thought that employment wasn't really like a goal for some of their patients, and maybe they were reluctant to listen, I guess, about IPS because they don't feel that employment is something their patients are working towards. 
Others described the challenges of offering IPS to patients who weren't regularly engaging with a service, although the zero exclusion criterion includes people who are not adherent to treatment:

S6: ...for patients that have not engaged and were discharged because we can't offer them a service, there's just nothing to offer them ... they probably wouldn't have been offered IPS because they wouldn't have engaged with the regular service to start with.

Staff also reported that the timing for IPS should come after a certain level of stability had been achieved, via other therapeutic interventions which they felt was their primary job role: S12:... Sort of thought actually this person is particularly unstable and yes we want to encourage them to work, but actually they probably need to engage with us and do a bit more therapy.

Therefore, although occupation is a significant facilitator to recovery for mental health, this participant regards therapy as the primary intervention, and is therefore working from a medical model of care, which could lack of focus on employment in a person's clinical treatment and recovery journey. This prioritisation of therapy is not only evident from staff narrative though. One patient believed that any success of the programme was down to the counselling group he attended that showed him peers who had achieved success despite their struggles:

P1: Group therapy gave me a lot more confidence seeing that there were people in the group that perhaps struggled more with confidence or, and that they were still functioning members of society and perhaps I need to give myself a kick up the backside and go do something ... 
These organisational level barriers have been supported in the literature which cites negative attitudes among managers and clinicians about the feasibility of work for people with mental illness (Bond et al., 2001; Van Erp et al., 2007; Hasson et al., 2011; Bonfils et al., 2017; Bergmarka et al., 2018), limited knowledge of IPS among clinicians (Shafer et al.,1999), and negative attitudes towards employment among people with mental illness (Crane-Ross et al., 2000). There is also an individual level barrier to IPS, in that patients may fear the transition to work will have a negative impact on them (Rinalidi et al., 2010):

\section{P3: I basically told the employment specialist that I needed a month, I'm just not going to contact her, not hear from you for a month, I need to reset, I need to not apply to anything and just take it easy for a while.}

However, enablers to recovery includes having a meaningful life, hope, empowerment and social integration (Burhouse et al., 2015) all of which occupation can provide, and can provide structure, and improve self-esteem (Boyce et al., 2008). These enablers are evident in patient's narratives who believed that the activities they did brought benefits to their lives including providing some meaning and focus and to motivate them to engage in purposeful activity during their day:

P1: I kind of wanted a job and to feel some meaning in my life again, to have a
purpose, umm I didn't know how that was going to work.

Occupation as an enabler to recovery was also acknowledged by staff:

S5: He needs less support and that all comes together you know and the staff they recognise that he's out, he's doing stuff meaningful to his day, he's got a schedule, he's got a routine you know and I really hope we can just build on that. 


\begin{abstract}
An individual level barrier to the success of an IPS program is that the patient group has a culture of low expectation (Rinalidi et al., 2010). The employment specialist through the provision of support can counteract this and increase a patient's self-esteem so that they feel that they can apply for work:
\end{abstract}

\begin{abstract}
P3: ... led to me handing out some CVs at, at different pubs and I got an interview at, well I think I handed out... I think 3 CV's and I got 2 interviews...
\end{abstract}

However, some staff report having a conversation with their patients about employment and when the patient has been interested has referred them on:
S9: I haven't had much experience in finding any work for patients because not many of mine have been that interested in finding work. Those that have, I've just passed straight over to the IPS team and I haven't done a great deal really.

Furthermore, when patients were referred and accessed IPS, and thus reached good fidelity, staff perceived employment positively:

S3: In my opinion it's something that is incredibly overlooked, that seems so simple.

\begin{abstract}
Another exclusion based on staff perspectives was the lack of work experience, qualifications or CVs amongst their patients:

S2: The lack of work experience that people have, so for a lot of the client group that we have, they might be in their mid to late thirties, might be younger than that but have no work history ... they get caught in you know just thinking that work is not an option for them and their confidence is poor, their numeracy and literacy is poor...
\end{abstract}


However, factors such as gaining work experience and writing a CV are part of the IPS programme.

ES: ... we're working with people that have no CV to be able to demonstrate to employers that they're capable of working so I think there have been some useful adaptions made ... unpaid voluntary work's been approached and that's actually been a, a really helpful way of getting people a $C V$ started.

Integration of Rehabilitation with Mental Health Treatment through Team Assignment: For IPS to be successfully implemented, the Employment Specialist must be fully integrated within the mental health team that they are working with. This includes attending mental health treatment meetings, and having regular communication with the mental health practitioners. It appears in the narrative that some staff did not see IPS as integrated, and that it is external to their rehabilitation work:

S10: ... maybe it would be better and could actually add more to it if you had a better dialogue between [the employment specialist] and us about what [the employment specialist was] currently doing and where [the employment specialist was] at and also hearing from [the employment specialist], what's useful and what's not...

Staff also discussed the challenges of fitting in a discussion about a patient's employment aspirations and how the IPS service could assist into the time-limited service that they offered to patients:

S3: ... it wouldn't be appropriate for an IPS worker to sit in on therapy sessions, so that must be tricky and I think probably the barrier then is like well do you have to 
create another forum to talk about people... in the limited time that you have, you don't want to add that many more meetings than you have to.

Therefore, this participant regards the IPS worker as external to their work. This barrier has been borne out in the literature which cites scepticism about the organisational fit of IPS and difficulties in integrating it within mental health teams (Bond et al., 2001; Van Erp et al., 2007; Hasson et al., 2011; Bonfils et al., 2017; Bergmarka et al., 2018). This organisational level fit barrier is also demonstrated in the below:

S12: I think so yeah, enough time for people to get their head around it [the IPS service], think how it was going to work, there was enough sort of warning beforehand and to sort of ask questions have fears allayed sort of thing before getting going with it.

Staff were generally unclear about the appropriateness of IPS within their services, thus preventing integration. This appears to have been exacerbated by pre-existing attitudes to IPS, and some of the ways in which IPS was communicated and promoted. Members of staff recalled how a senior member of staff made comments that were 'unhelpful':

\author{
S1: ...I think it was a consultant who said that IPS has caused a patient to relapse and \\ go to prison but were unsure of who this person is, so we don't really have any \\ information.
}

Accounts such as this regarding IPS had a knock-on effect amongst other staff about the benefits of IPS and other forms of supported employment for this patient group: 


\begin{abstract}
S6: ... saying negative things about a service it then makes it more difficult to establish things... I think there was a danger of it leaving other staff with a negative view of IPS and the notion of paid employment.
\end{abstract}

These statements infer that people were excluded due to fear of adverse effects, and limited knowledge of IPS among clinicians which is a cited barrier to implementation of IPS (Shafer et al.,1999). It also indicates that this fidelity factor was absent. If the employment specialist was fully integrated with regular communication these negative issues could have been resolved, as can be seen in the below:

S2: I think one of the huge positive factors was [the team leader] who was really keen to embed it and really supported the employment specialist from a clinical perspective, he's kept it on the agenda of all staff.

Where there was clearer communication of the benefits of employment and close working between the IPS employment specialist and staff integration was achieved:

\footnotetext{
S12: I think the clarity of information around what IPS was and what the aim of it would be I think helped get people on side I think. It definitely was a big plus having someone embedded within the team.
}

Once staff believe in IPS as a rehabilitation intervention, they found that having an employment specialist who would act as the person who knew and could support employment, when their own job had multiple priorities was extremely useful:

S3: when I worked in the team as an [job role] that was one of the biggest challenges was trying to support people to find that way back into work and to have somebody 


\begin{abstract}
Staff also commented that colocation of the employment specialist within teams enhanced their clinical work and the ability to support their patient:
\end{abstract}

\begin{abstract}
S5: you know she's around, ...even just catching up in the corridor you know if something springs to mind that you know she's just met with somebody, ...for example in the case with [Name] ... as soon as employment specialist knew that there was something maybe going awry that she was able to quickly come to me, then we could quickly look at 'ok how can we work through this, how can we work together with this'... so really that kind of collaborative working has been really positive.
\end{abstract}

Individualised job search: To ensure a good job match is achieved the search needs to be based on client's preferences and needs rather than what jobs are available. This fidelity criterion seems not to have been adhered to from the patient perspective, as they commented that the IPS service did not meet their expectations which led to challenges in seeing the potential benefits of the service. Two patients reported that their job search preferences were discarded, and this had a negative impact on their engagement with the service:

\begin{abstract}
P2: I felt like I was banging my head against a wall sometimes... I ended up applying for stuff almost to please IPS, it's like when you're on jobseekers [welfare benefits] or whatever and you have to apply to at least so many jobs a week and you apply to them with like no hope or no real want to get that job because it doesn't suit you but you've
\end{abstract}


got to tick these boxes and I was kind of doing that to some extent and then I just burnt out.

Job development - Frequent Employer Contact: Each Employment Specialist should make at least 6 face to face employer contacts per week on behalf of clients looking for work. Becker and colleagues (2008) argue that although this is important for fidelity, Employment Specialists may avoid this part of their job as they maybe nervous about contacting employers, and although clients are encouraged to participate in the job search, employment specialists should always offer to help if the client is struggling. This appears to be the case in the below narrative:

P1: I think the help was there, like employment specialist did do the CV for me but I was looking at perhaps becoming a [Industry job role] and how to get into that and employment specialist had limited knowledge on that subject... I don't expect her to know everything but so then employment specialist said to me well go find some companies that do that, whereas I expected the employment specialist to kind of find companies that would do that.

Job Development - Quality of Employer Contact: This fidelity criterion which follows the above, aims to learn the needs of the employer and to describe their client's strengths to ensure a good match. For example, from an employer's perspective fears regarding offending history, mental health, employability, and disclosure were reported. Although the Employment Specialist provided support to the employers such as responding to concerns regarding the patients' offending histories or mental health issues, it appeared that patients' mental health issues were less of a concern for employers than their offending histories. In 
particular, the type of offence, and the type of employment they could offer were of consideration:

E3: ...there's no way any kind of sex offence, no especially when you're dealing with public and staff... if it was things like theft and fraud, when you're working in a retail environment, that's something that you've.... I don't think I could.

\begin{abstract}
Disclosure: Employment specialists provide clients with accurate information and assist with evaluating their choices to make an informed decision regarding what is revealed to the employer. The type of the offence and level of offence were a key consideration in the employers' accounts. This was to the extent that if they had to decide to employ someone and had the prior knowledge about the offence, they would not employ them in the first instance. However, subjective ideas about the offence came into this, and different offences were perceived to have different levels of acceptability.
\end{abstract} E1:... To me, unless it's a serious offence then obviously that's different because you know you're dealing with members of the public and children and that's ... a different area for anybody.

E3: I think with offending it would be, if it was things like theft and fraud, when you're working in a retail environment, that's something that you've, I don't think I could.

Clinical staff also discussed the type of offence that some of their patients had committed, suggesting that it was of a level that would result in a barrier to employment. S10: ... I suppose the main barrier would be about how it fits in with our particular client group because the likelihood is that they have a conviction, that conviction is likely to have been a violent offence which could prevent them having contact with 
people that may be classed as vulnerable or being placed in certain situations that might restrict what it is they could access from an employment perspective.

The support provided by the Employment Specialist was appreciated by patients:

P1: ...she gave me the confidence to say it, like I ended up copping out and ended up writing a note and like leaving it on my manger's desk.

When this fidelity criterion is reached and the employers were supported by the employment specialist, and a good match made, employers were lenient, and supportive to the patient: E2: He didn't sort of want to come in. I think he was having a few problems and then he, what he did a few days later, he text me so I spoke to him I said 'well come try it again' $\ldots$

E1: I think you've got to have a little bit of give and take with them, when they've got anxiety problems and stuff, you know and because I knew..., I was bit more lenient and you know he's doing ok yeah...

Due to these issues however, it was acknowledged by the employers that they could only employ patients if they had the capacity to support them:

E5: ...comes down to budget and you know if you've got somebody that maybe is going to be off because they have an issue, it's going to make it very difficult, not only on us but everybody else in the store.

Work Incentives Planning: All clients should be offered an individualised work incentive plan which includes effects of working on welfare benefits and if they begin work are 
assisted in reporting earnings, and making decisions regarding changing hours. This was adhered to by the Employment Specialist:
ES: .... so I tried to overcome that by obviously liaising with the Jobcentre to use their benefits calculations to show to the patients that actually no you're not going to be worse off you can actually be better off if you're doing a certain amount of hours and so on.

\begin{abstract}
However, although this service is provided via IPS, concerns about the impact of IPS on patient entitlement to receive welfare benefits still featured in staff accounts:

S: I think a lot of the problem that we have is people are worried about losing their benefits... and that's the biggest stumbling block I found for nearly all of my patients.
\end{abstract}

\begin{abstract}
In the literature, welfare benefits appear as both a structural barrier, i.e. regulations for social insurance and employment, and an individual barrier, i.e. concerns about the impact of IPS on their welfare benefits (Hasson et al., 2011).
\end{abstract}

Community Based Services: IPS should be provided to clients in natural community based settings as research has demonstrated that employment specialists who carry out their job responsibilities away from their office help more people into employment. This was appreciated by patients:

P1: I think one of the things is like helpful was that you were able to like, you were quite flexible in when you were able to meet up, ....., I mean employment specialist came out to the local [café] near me which is really great.. 
Furthermore, by moving the IPS into community settings, some bureaucratic barriers could be avoided. For example, one staff member mentioned that NHS policies mean that only staff can use the computers. This, they believed, prevented the employment specialist and patient from collaborating on job searching and applications together.

\section{Discussion}

There is a dearth of studies that examined the barriers and facilitators for IPS implementation in forensic settings. A study in the USA (Bond et al., 2015) reported that barriers to employment were disengagement, current substance abuse, general medical problems, lack of work skills, and criminal justice system problems. A UK based project that aimed to develop an IPS programme for offenders with mental health problems identified further barriers, including funding for additional employment support costs, such as criminal record checks, uniforms, and travel to interviews (Samele et al., 2018). These authors identified flexibility and a willingness to consider alternative options to employment, like volunteering and education, as the key to successful implementation of IPS within forensic settings.

Worthy of consideration are findings from studies conducted in general community mental health settings. To an extent, our findings mirror those reported in a study of IPS implementation in adult mental health settings in the UK which identified mental health symptoms, effects of medication and previous illness record, and lack of work experience as major barriers (Boycott et al., 2015). Other barriers cited included anxiety, lack of confidence, and concerns regarding fitting in with colleagues (Boycott et al, 2015). Another UK study, reported no statistically significant differences between IPS and traditional vocational services for individuals with severe mental illness in the community (Howard et al., 2010). However, this lack of difference was largely attributed to the reported suboptimal 
implementation of the IPS in terms of poor integration within mental health services, and economic disincentives leading to lower levels of motivation in patients, and professionals. This lack of engagement by services and professionals is underlined by a recent Swedish study (Bergmarka et al., 2018) which identified lack of engagement from collaborating partners, lack of interest in IPS among professionals, and challenges associated with embedding IPS workers within services as barriers to implementation of IPS in community settings.

Furthermore, employers may have negative attitudes about employing those with offending histories depending on the type of the offence they have committed, with about $70 \%$ of employers in one study (Haslewood-Pocsik et al, 2008) being shown to be averse to employing those with a conviction for arson or sex offences.

Our study identified important barriers to IPS implementation including competing priorities between IPS and psychological therapies and concerns among staff about the impact of IPS on entitlement to welfare benefits. Offending history is as a key issue from employers' perspective. One important barrier is that NHS policies mean that only staff can use the computers. This can prevent the employment specialist and patient from collaborating on job searching and applications together.

Regardless of the proven benefits of employment for recidivism and mental health, another barrier for IPS implementation was the staff perspective that their patient was not work ready. Staff made the determination if the patient was ready for IPS, and held back referrals. Therefore, there are power dynamics in deciding whether a patient is ready for employment. Further barriers to IPS were due to the subjective opinions regarding offending histories held 
by employers. Although these barriers were minimised by the support and information provided by the Employment Specialist, they were still evident from the interviews.

Facilitators to implementation included clear communication of the benefits of IPS, close liaison with clinicians, and positive attitudes toward IPS among some clinicians and patients. Patients cited enhancing their confidence and motivation to engage in purposeful activity as the main benefits of IPS. Patients cited enhancing confidence as the main benefit of IPS. Additionally, the study helped raise the profile of the IPS model among stakeholders.

The challenges associated with implementing IPS in forensic settings negatively impact IPS fidelity which is known to account for some of the variance in outcomes in IPS studies. However, it is important to consider other factors such as professional skills (Drake et al., 2006) particularly building a therapeutic relationship with the patient (Catty et al, 2008). The development of IPS specifically for individuals with offending histories is an adaptation suggested by some authors (Bond et al, 2015). IPS augmentation using motivational strategies and developing IPS teams with expertise in working with offender groups have been suggested to improve employment outcomes (Bond et al, 2015). However, the findings of our study do not provide justification for making adaptations to the IPS model.

The barriers identified in this study are not insurmountable. Future studies need to consider enhancing staff training and intensifying IPS practices, for example, by providing peer support and sharing more examples of people securing employment to address attitudes and beliefs of clinicians, and ensuring a clear focus from clinical and employment staff on helping a participant manage personal information which includes talking about offending history. Furthermore, consideration of work readiness should be undertaken via a discussion 
between the employment specialist and the patient, rather than the current practice of clinical staff overriding the patient's employment ambitions. Furthermore, when introducing an IPS service there needs to be better information about how welfare benefit payments would be affected if they considered IPS. Enhancing facilitators to IPS implementations is worthy of consideration, for instance, through robust interdisciplinary collaboration, organisational support and clear communication of the benefits of IPS to all stakeholders. Furthermore, considerations need to be given to developing, or joining existing IPS learning collaboratives. Learning collaboratives foster a culture of collaboration between IPS programmes through the collection of data concerning programme implementation and outcomes, sharing of knowledge, provision of training and technical support as well as research and innovation (Becker et al., 2014; Margolies et al., 2015).

\section{Study strengths and weaknesses}

This study provides unique insights into the challenges associated with implementation of IPS in a community forensic setting, an area that has attracted little attention in the literature. However, the study suffered a number of limitations, including that IPS was implemented on a small scale and over a relatively short period of time as part of a clinical trial. A small number of patients and employers agreed to take part in the study, and most of the employers had no direct experience of the IPS model. Future studies should examine the barriers and facilitators to IPS implementation in other forensic or criminal justice settings, using larger samples. This would help form a better understanding of the barriers and facilitators to implementation of IPS in these settings. 


\section{Conclusion}

Implementation of IPS in a community forensic setting is a complex process that requires robust planning and collaboration. The findings of this study show that the barriers and facilitators to implementing high-fidelity IPS in forensic settings are very similar to those encountered in community mental health settings, but that an offending history combined with a mental illness is an additional barrier. Practitioners and funders need to take this into account when implementing IPS programmes in community forensic settings. Deriving tangible benefits from an IPS service requires considerable investment on the part of health services as well as ongoing support from both clinicians and service managers. Besides, a considerable amount of work is required to engage potential employers, who are seemingly more flexible and sympathetic towards employing patients with mental health problems than those with offending histories. Additionally, further work is needed to develop an IPS learning collaborative in the UK to help understand and overcome the similar and unique barriers to IPS implementation in forensic settings. Implementation of high fidelity IPS services requires technical support to educate clinicians about the value of employment and how IPS differs from other forms employment support. Work with commissioners of healthcare is often needed to align contracts so they support the implementation of IPS practices. Finally, since the underpinning values of IPS are compatible with those of occupational therapy, for instance, in terms of the value of meaningful occupation and leading a productive live in the society (Auerbach, 2002), we argue that the findings of this study are potentially relevant to the clinical practice of occupational therapy.

\section{Key findings}


- Barriers to IPS implementation are competing interests between IPS and psychological therapies, and concerns about its impact on welfare benefits, and facilitators are interdisciplinary collaboration and organisational support.

- Patients cited enhancing confidence as the main benefit of IPS.

- Offending history is as a key issue from employers' perspective.

\author{
What the study has added \\ This study identified barriers and facilitators to IPS implementation in community forensic \\ mental health settings. The findings can potentially help service provider implement and \\ deliver high fidelity IPS programmes.
}




\section{References}

Auerbach ES (2002) The Individual Placement and Support Model vs. the Menu Approach to Supported Employment: Where Does Occupational Therapy Fit In? Occupational Therapy in Mental Health 17(2): 1-19.

Becker DR, Torrey WC, Toscano R et al. (1998) Building recovery-oriented services: Lessons from implementing Individual Placement and Support (IPS) in community mental health centers. Psychiatric Rehabilitation Journal 22 (1): 51-54.

Becker DR, Swanson SJ, Bond GR et al. (2008) Supported Employment Fidelity Scale. Lebanon, NH: Dartmouth Psychiatric Research Center.

Becker DR, Drake RE and Gary R. Bond GR (2014) The IPS Supported Employment Learning Collaborative. Psychiatric Rehabilitation Journal 37 (2): 79-85.

Bergmarka M, Bejerholmb U, and Markströma U (2018) Critical Components in Implementing Evidence-based Practice: A Multiple Case Study of Individual Placement and Support for People with Psychiatric Disabilities. Social Policy and Administration 53(3): 790-808.

Bejerholm U, Areberg C, Hofgren C et al. (2015) Individual Placement and Support in Sweden-A randomized controlled trial. Nordic Journal of Psychiatry 69:1, 57-66. Bond GR, Becker DR, Drake RE et al. (2001) Implementing supported employment as an evidence-based practice. Psychiatric Services, 52: 313-322.

Bond GR, Drake RE and Becker DR (2008) An update on randomized controlled trials of evidence-based supported employment. Psychiatric Rehabilitation Journal 31: 280289. 
Bond GR, Drake RE and Becker DR (2012) Generalizability of the Individual Placement and Support (IPS) model of supported employment outside the US. World Psychiatry $11: 32-39$

Bond GR, Kim SJ, Becker DR et al. (2015) A Controlled Trial of Supported Employment for People With Severe Mental Illness and Justice Involvement. Psychiatric Services 66, 1027-1034. doi: 10.1176/appi.ps.201400510.

Bonfils IS, Hansen H, Dalum et al. (2017) Implementation of the individual placement and support approach - facilitators and barriers. Scandinavian Journal of Disability Research 19(4): 318-333.

Boycott N, Akhtar A and Schneider J (2015) “'Work is good for me'”: views of mental health service users seeking work during the UK recession, a qualitative analysis. Journal of Mental Health 24(2): 93-97.

Boyce M, Secker J, Johnson R et al. (2008) Mental health service users' experiences of returning to paid employment. Disability \& Society 23(1):77-88.

Braun V and Clarke V (2006) Using thematic analysis in psychology. Qualitative Research in Psychology, 3(2): 77-101.

Burhouse A, Rowland M, Marie Niman H et al. (2015) Coaching for recovery: a quality improvement project in mental healthcare. BMJ Open Quality 4: u206576.w2641.

Burns T, Catty J, Becker T et al. (2007) The effectiveness of supported employment for people with severe mental illness: a randomised controlled trial. The Lancet 370: 1146-1152.

Catty J, Lissouba P, White S at al. (2008) Predictors of employment for people with severe mental illness: results of an international six-centre randomised controlled trial. British Journal of Psychiatry 192: 224-231. 
Centre for Mental Health (2010) Briefing 42: Beyond the gate: securing employment for offenders with mental health problems. London: Centre for Mental Health.

Crane-Ross D, Roth D and Lauber BG (2000) Consumers' and case managers' perceptions of mental health and community support service needs. Community Mental Health Journal 36: 161-178.

Crowther R, Marshall M, Bond G et al. (2001) Vocational rehabilitation for people with severe mental illness. Cochrane Database of Systematic Reviews. Issue 2. [DOI: 10.1002/14651858.CD003080].

Corbière M, Lanctôt N, Lecomte T et al. (2010) A Pan-Canadian evaluation of supported employment programs dedicated to people with severe mental disorders. Community Mental Health Journal, 46(1): 44-55.

Damschroder LJ, Aron DC, Keith RE. et al. (2009) Fostering implementation of health services research findings into practice: a consolidated framework for advancing implementation science. Implementation Science 4(1): 50.

Drake RE, Becker DR, Bond GR et al. (2003) A process analysis of integrated and nonintegrated approaches to supported employment. Journal of Vocational Rehabilitation 18: $51-58$.

Drake RE, Bond GR and Rapp C (2006) Explaining the variance within supported employment programs: comment on "What predicts supported employment outcomes?'. Community Mental Health Journal 42: 315-318.

Durcan G, Allan J and Hamilton IS (2018) From prison to work: A new frontier for Individual Placement and Support. Centre for Mental Health: London-UK.

Durlak JA and DuPre EP (2008) Implementation Matters: A Review of Research on the Influence of Implementation on Program Outcomes and the Factors Affecting Implementation. American Journal of Community Psychology 41:327-350. 
Frederick DE and VanderWeele TJ (2019) Supported employment: Meta-analysis and review of randomized controlled trials of individual placement and support. PLoS One. 14(2): $e 0212208$.

Hamilton IS (2016). Employment of ex-prisoners with mental health problems: a review. Journal of Criminological Research, Policy and Practice, 2(1): 40-53.

Handler J, Doel K, Henry A et al. (2003) Rehab rounds: implementing supported employment services in a real-world setting. Psychiatric Services, 54: 960-962.

Haslewood-Pocsik I, Brown S and Spencer JA (2008) Not so well lit path: employers' perspectives on employing ex-offenders. The Howard Journal 47(1): 18-30.

Hasson H, Andersson M and Bejerholm U (2011) Barriers in implementation of evidencebased practice: Supported employment in Swedish context. Journal of Health Organization and Management 25(3): 332-345.

Heslin M, Howard L, Leese M et al. (2011). Randomised controlled trial of supported employment in England: 2 year follow-up of the Supported Work And Needs (SWAN) study. World Psychiatry 10:132-137.

Hoffman H, Jäckel D, Glauser S et al. (2012) A randomized controlled trial of the efficacy of supported employment. Acta Psychiatrica Scandinavica 125:157-167.

Howard LM, Heslin M, Leese M et al. (2010) Supported employment: randomised controlled trial. British Journal of Psychiatry 196: 404-411.

Kenney-Herbert J, Taylor M, Puri R et al. (2013) Standards for Community Forensic Mental Health Services. Quality Network for Forensic Mental Health Services. Royal College of Psychiatrists: London - UK. Available at: http://www.antoniocasella.eu/archipsy/KENNEY-HERBERT_APR13.pdf 
Kinoshita Y, Furukawa TA, Kinoshita K et al. (2013) Supported employment for adults with severe mental illness (Review). Cochrane Database of Systematic Reviews, Issue 9. Art. No.: CD008297.

Joint Commissioning Panel for mental health (2013) Guidance for commissioners of forensic mental health services. Available at: https://www.jcpmh.info/wpcontent/uploads/jcpmh-forensic-guide.pdf

Judge J, Harty M and Fahy T (2004) Survey of community forensic psychiatry in England and Wales. Journal of Forensic Psychiatry \& Psychology 15: 244-253.

Latimer E (2010) An effective intervention delivered at sub-therapeutic dose becomes an ineffective intervention. British Journal of Psychiatry 196(5):341-342.

Margolies PJ, Broadway-Wilson K, Gregory R et al. (2015) Use of Learning Collaboratives by the Center for Practice Innovations to Bring IPS to Scale in New York State. Psychiatric Services 66:4-6.

Metcalfe JD, Drake RE and Bond GR (2018) Economic, Labor, and Regulatory Moderators of the Effect of Individual Placement and Support Among People with Severe Mental Illness: A Systematic Review and Meta-analysis. Schizophrenia Bulletin 44 (1): 2231.

Michon H, van Busschbach JT, Stant AD et al. (2014) Effectiveness of Individual Placement and Support for People With Severe Mental Illness in the Netherlands: A 30-Month Randomized Controlled Trial. Psychiatric Rehabilitation Journal 37(2): 129-136.

Ministry of Justice (2013) Analysis of the impact of employment on re-offending following release from custody, using Propensity Score Matching. Available at: https://assets.publishing.service.gov.uk/government/uploads/system/uploads/attachme nt_data/file/217412/impact-employment-reoffending.pdf (accessed 28 January 2019). 
Modini M, Tan L, Brinchmann B et al. (2016) Supported employment for people with severe mental illness: systematic review and meta-analysis of the international evidence. British Journal of Psychiatry 209 (1): 14-22.

Nygren U, Markström U, Svensson B et al. (2011) Individual Placement and Support - a model to get employed for people with mental illness - the first Swedish report of outcomes. Scandinavian Journal of Caring Sciences 25(3): 591-598.

Pager D (2003). The mark of a criminal record. American Journal of Sociology 108: 937975.

Richter D, Hoffman H (2019) Effectiveness of supported employment in non-trial routine implementation: systematic review and meta-analysis. Social Psychiatry and Psychiatric Epidemiology 54(5): 525-531.

Rinaldi M, Perkins R, Glynn E et al. (2008) Individual Placement and Support: From research to practice. Advances in Psychiatric Treatment 13: 50-60.

Rinaldi M, Miller L, Perkins R (2010) Implementing the individual placement and support (IPS) approach for people with mental health conditions in England. International Review of Psychiatry 22(2): 163-172.

Samele C, Forrester A and Bertram M (2018) An evaluation of an employment pilot to support forensic mental health service users into work and vocational activities. Journal of Mental Health 27(1):45-51.

Sneed Z, Koch DS, Estes H et al. (2006) Employment and psychosocial outcomes for offenders with mental illness. International Journal of Psychosocial Rehabilitation 10(2): 103-12.

Shafer MS, Pardee R and Stewart M (1999) An assessment of the training needs of rehabilitation and community mental health workers in a six-state region. Psychiatric Rehabilitation Journal 23: 161-70. 
Sveinsdottir V and Bond GR (2017) Barriers to employment for people with severe mental illness and criminal justice involvement, Journal of Mental Health, DOI: 10.1080/09638237.2017.1417556.

Talbot E, Vollm B and Khalifa N (2017) Effectiveness of Work skills programmes for offenders with mental disorders: A Systematic Review. Criminal Behaviour and Mental Health Journal 27(1): 40-58.

Talbot E, Bird Y, Russell J et al. (2018) The barriers and facilitators to implementation of Individual Placement and Support (IPS) into community forensic mental health settings. The British Journal of Occupational Therapy 81(6): 338-347.

Van Erp NHJ, Giesen F, Van Weeghel J. et al. (2007) A multisite study of implementing supported employment in The Netherlands". Psychiatric Services 58(11): 1421-1426.

Western B (2002) The impact of incarceration on wage mobility and inequality. American Sociological Review 67: 526-546. 
Table 1: IPS Fidelity Scale scores at the end of implementation

\begin{tabular}{|r|l|c|}
\hline & Domain & $\begin{array}{c}\text { Fidelity } \\
\text { Review } \\
\text { Score }\end{array}$ \\
\hline & Staffing & \\
\hline 1 & Number on caseload & 5 \\
\hline 2 & Employment Services Staff & 5 \\
\hline 3 & Vocational Generalists & 5 \\
\hline & Organisation & \\
\hline 4 & Integration with CMHT through team assignment & 5 \\
\hline 5 & Integration with CMHT through frequent contact & 5 \\
\hline 6 & Collaboration between employment specialists and Job & 5 \\
\hline 7 & Centre Plus & 5 \\
\hline 8 & Rocational unit & 4 \\
\hline 9 & Zero exclusion criteria & 3 \\
\hline 10 & Mental Health Agency focus on competitive employment & 4 \\
\hline 11 & Executive Team support & 4 \\
\hline & Services & 4 \\
\hline 12 & Work incentives planning & 5 \\
\hline 13 & Disclosure & 5 \\
\hline 14 & Ongoing, work-based vocational assessment & 5 \\
\hline 15 & Rapid search for competitive job & 4 \\
\hline 16 & Individualised job search & 0 \\
\hline 17 & Job development - Frequent employer contact & 5 \\
\hline 18 & Job development - Quality of employer contacts & 5 \\
\hline 19 & Diversity of job types & 5 \\
\hline 20 & Diversity of employers & \\
\hline & & 5 \\
\hline
\end{tabular}




\begin{tabular}{|c|l|c|}
\cline { 2 - 2 } 21 & Competitive jobs & $0^{*}$ \\
\hline 22 & Individualised follow-along supports & $0^{*}$ \\
\hline 23 & Time-unlimited follow-along supports & $0^{*}$ \\
\hline 24 & Community-based services & $0^{*}$ \\
\hline 25 & Assertive engagement and outreach by integrated team & 3 \\
\hline & Total score & 85 \\
\hline & Maximum IPS score & 125 \\
\hline
\end{tabular}

*not assessed due to lack of sufficient referrals at that stage. 